\title{
Comparison Method of PI, PID and Fuzzy Logic Controller to Maintain Speed Stability in Single Phase Induction Motors
}

\author{
Irianto $^{1, \mathrm{a}}$, Farid Dwi Murdianto ${ }^{1, \mathrm{~b}, *}$, Epyk Sunarno ${ }^{1, \mathrm{c}}$, Dewinta Dwi Proboningtyas ${ }^{1, \mathrm{~d}}$ \\ ${ }^{1}$ Department of Electrical Engineering, Politeknik Elektronika Negeri Surabaya, Jl. Raya ITS, Keputih, Kec. Sukolilo, \\ Kota Surabaya, Jawa Timur 60111, Indonesia

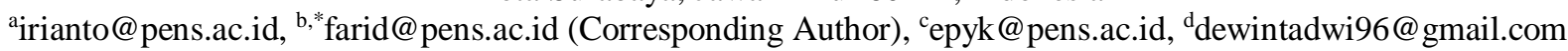

\begin{abstract}
Induction motor speed control is one of the operating conditions that are often used so that feedback with a low error rate is required. To achieve this control aim, PI and PID controls have been widely implemented for single phase induction motors. This control is commonly dictated by parameters of $\mathrm{Kp}, \mathrm{Ki}$ and $\mathrm{Kd}$. PI and PID controls can cover a variety of desired response conditions, but these controls still have weaknesses in the tuning process. The tuning process used still has a fairly large error value. So in this case it is required an intelligent controls to meet the desired motor speed response specifications. The performance of motor speed regulation was evaluated using a comparison between PI and PID control with Fuzzy in a closed loop. With a setting point of $1500 \mathrm{rpm}$, for PI control, with $K p=7.32$ and $K i=0.005$ can obtain motor speeds up to $1499 \mathrm{rpm}$. While PID control with $\mathrm{Kp}=\mathbf{0 . 9 5}, \mathrm{Ki}=\mathbf{0 . 0 0 5}$ and $\mathrm{Kd}=0.04$ can obtain similar speeds of $1492 \mathrm{rpm}$. Fuzzy control can obtain an output of $1490 \mathrm{rpm}$. Fuzzy control is able to produce a settling time of 0.25 seconds and a steady error of $0.67 \%$.
\end{abstract}

Keywords-Fuzzy Logic Controller, PI Controller, PID Controller, Single Phase Induction Motor

\section{Introduction}

Single phase induction motors are the most common motors used in home appliances [1]. Of course, the speed level of the motor will have an effect on supporting the common jobs of household activities itself. However, the speed setting on the induction motor is still a problem. The objective of controlling induction motor speed is to achieve the maximum torque and efficiency [2]. However, speed control gives the opposite side to the properties of the induction motor. Normally, an induction motor has a difficulty maintaining their speed. It delivers a quite high error rate when the induction motor speed setting is operated with an open system. Error $(\mathrm{e}(\mathrm{t}))$ is the difference between the reference value and the measurable corresponding value [3]. One way to overcome this error is by providing a control/technique control as feedback [4]. From several applied applications, PI and PID controller are two controllers that are often employ due to the simple controller structure and practical. PI and PID controller has three parameters used, the variable parameters namely proportional, integral and derivative $(\mathrm{Kp}, \mathrm{Ki}$, Kd) [5]. PI parameters can be determined via parameter tuning. Common method used as a tuning is analytics method. In general, it is often difficult to determine the optimal PI and PID parameters with analytics method, therefore the output response is resulting in a closed system will be inappropriate (causing a large enough oscillation), even though PI and PID controller are expected to obtain a stable output response [6].

Currently, there has been several developments of smart controller, for example a fuzzy logic controller [7]. Fuzzy logic controller is a controller that utilizes the system decision-making [8]. Several references show the output of Fuzzy controller provides low rise time with no overshoot excess and low steady state error allows rare oscillations. It allows to control a single phase induction motor to be able operate optimally in every condition. 


\section{Research Methodology}

\section{A. Motor Speed Control Method}

A voltage source with a sinusoidal wave as the reference signal is applied, this voltage source uses a triangular wave as a carrier signal [9]. This carrier signal frequency is called switching frequency. The switching frequency can determine the length of time on the pulse when open the foot gate on the switching component besides that it also affects the output voltage drop of the inverter [10].

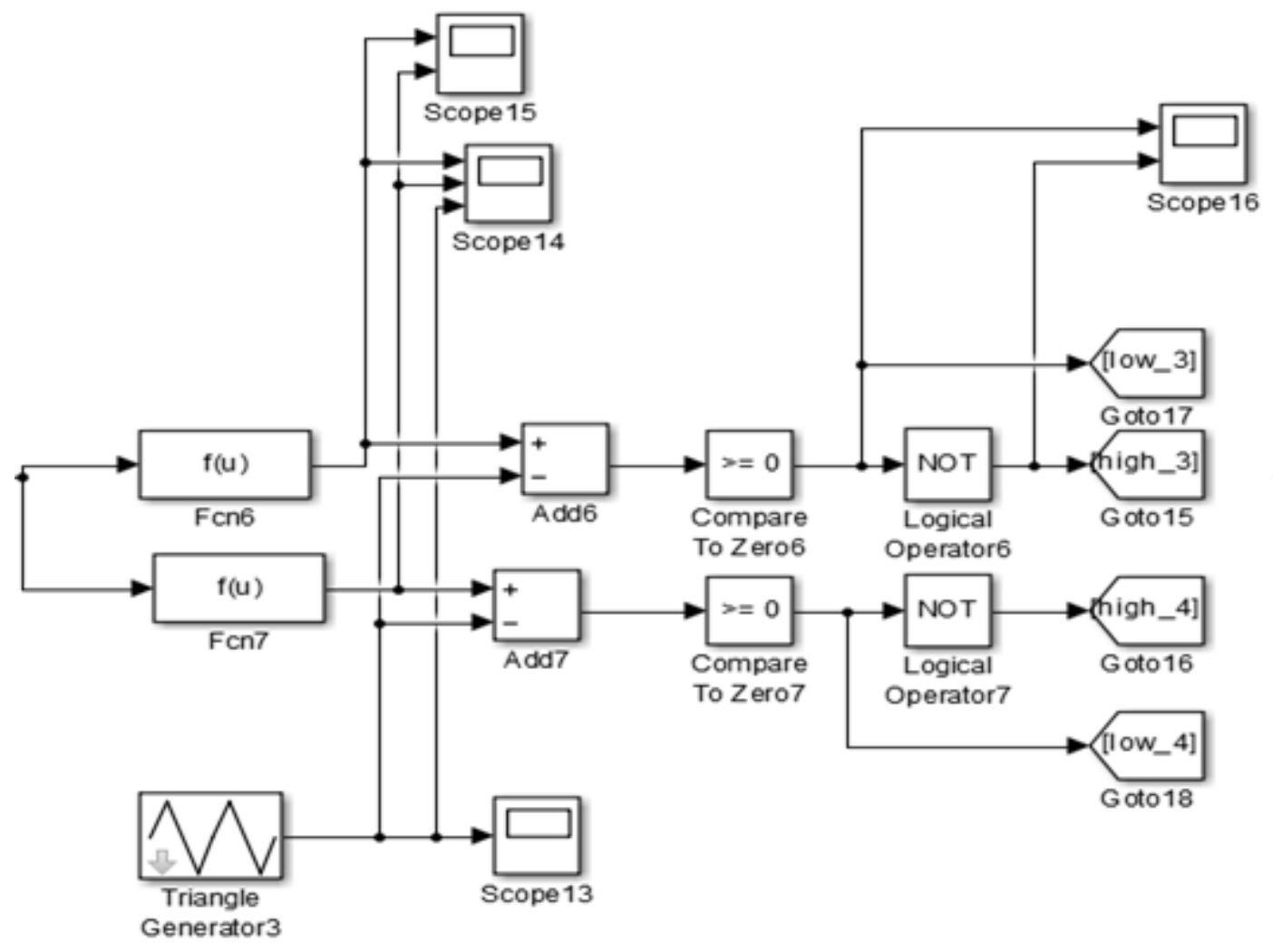

Figure 1. Scheme of SPWM in the MATLAB Simulation

In Figure 2, it can be seen that there are two fcn inputs, the fcn is used to form a reference signal (sine signal). The reference signal can be formed through the equation (1) and (2).

$$
\begin{gathered}
\text { Fcn } 1=u[1] * \sin \left(u[2] * 2 * \mathrm{pi}^{*} \mathrm{u}[3]\right) \\
\mathrm{Fcn} 2=\mathrm{u}[1] * \sin (\mathrm{u}[2] * 2 * \mathrm{pi} * \mathrm{u}[3]+\mathrm{pi})
\end{gathered}
$$

Where:

$\mathrm{U}[1]=\mathrm{MA}$ (modulation index of the SPWM signal)

$\mathrm{U}[2]=$ frequency

$\mathrm{U}[3]=$ clock

To be able to run the v/f method, the first thing to do is determine the setting point of the plant.

$$
\begin{aligned}
& \mathrm{NS}=\frac{120 F c}{P} \\
& 1500 \quad=\frac{120 F c}{2} \\
& \mathrm{Fc}=25 \mathrm{~Hz} \\
& \text { Where: } \\
& \mathrm{NS}=\text { the expected setting point } \\
& \mathrm{Fc}=\text { frequency control } \\
& \mathrm{P}=\text { the number of motor poles }
\end{aligned}
$$

Where:

$\mathrm{Fc}=$ frequency control

After getting the $\mathrm{Fc}$ value, it will be compared with the frequency. Therefore, it could obtain the MA value.

$$
\text { MA }=\frac{F c}{F f}
$$




$\begin{array}{ll}\text { MA } & =\frac{25}{50} \\ \text { MA } & =0,5\end{array}$

This MA will be the basis for the formation of the pulse signal which will form the duty cycle. (When MA $=1$, duty cycle $=100 \%$ ) [11]. The formation of duty cycle will be affecting the output voltage of the inverter. Which is the input for the motor.

$$
\begin{aligned}
\text { Vo } & =M A \times V s \\
\text { Vo } & =0.5 \times 220 \\
\text { Vo } & =110 \mathrm{~V}
\end{aligned}
$$

Where:

Vo $=$ Output voltage of inverter

$\mathrm{Vs}=$ Voltage from the grid (PLN)

From equation (5) and (3) it can be seen that the input voltage of motor is $110 \mathrm{~V}$, and the frequency is $25 \mathrm{~Hz}$. This can be proven by the V/f method, which has a ratio equal to 4.4. This ratio is a fixed ratio, regardless of the value of the voltage and frequency.

\section{B. Power Converter}

Single phase inverter is used to convert DC voltage into AC voltage [12]. Single phase inverter consists of 4 switching components, either IGBT or Mosfet [13]. The output voltage of inverter is in the form of an AC voltage, but this wave still has a sufficiently large THD of current and voltage, so that it is not a pure sinusoidal wave [14].

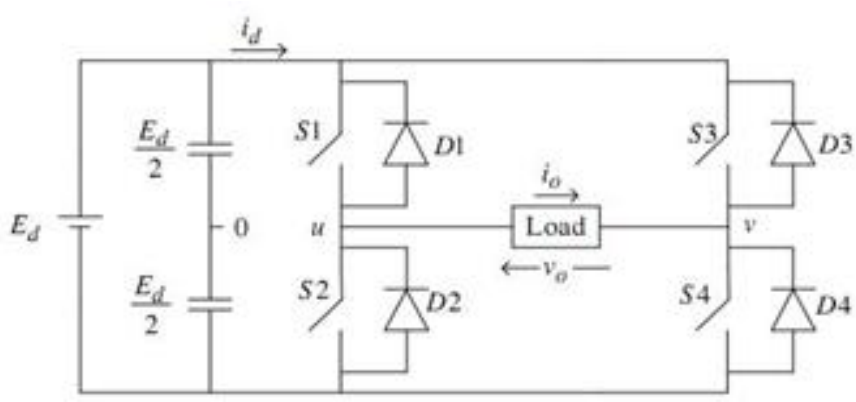

Figure 2. Single phase inverter circuit
Figure 2 is shown a single phase full bridge inverter, which consists of 4 switch devices. It can be seen in the single phase inverter schematic circuit, that there is a freewheeling diode which is installed in parallel to each of the inverter electronic switch devices. This diode serves to prevent the emergence of reverse current from inductive loads to the inverter voltage source which can damage electronic switch devices used in single phase inverters.

The inverter design functions to produce voltage 220 Volt AC with a frequency $50 \mathrm{~Hz}$ [15]. The switching method generated by the driver on the ignition signal of single phase inverter using IC IR 2111 is the unipolar method (PWM). In the driver single phase inverter circuit, before the signal enters IC IR 2111 there is an optocoupler, namely IC FOD 3182 which functions as a safety between the driver circuit and the microcontroller as well as signal conditioning to produce a pulse voltage 12 Volts as an ignition signal on the electronic switch contained in the single phase inverter.

\section{Control Feedback}

This part discusses the design of 3 controllers; PI, PID and Fuzzy Logic Controller.

\section{Design of PI Controller}

Calculating PI controller will use an analytic method. The main purpose is to determine the parameters of $\mathrm{Kp}$ and $\mathrm{Ki}$ of the plant [16]. Figure 3 is a response curve for design PI controller using the analytic method.

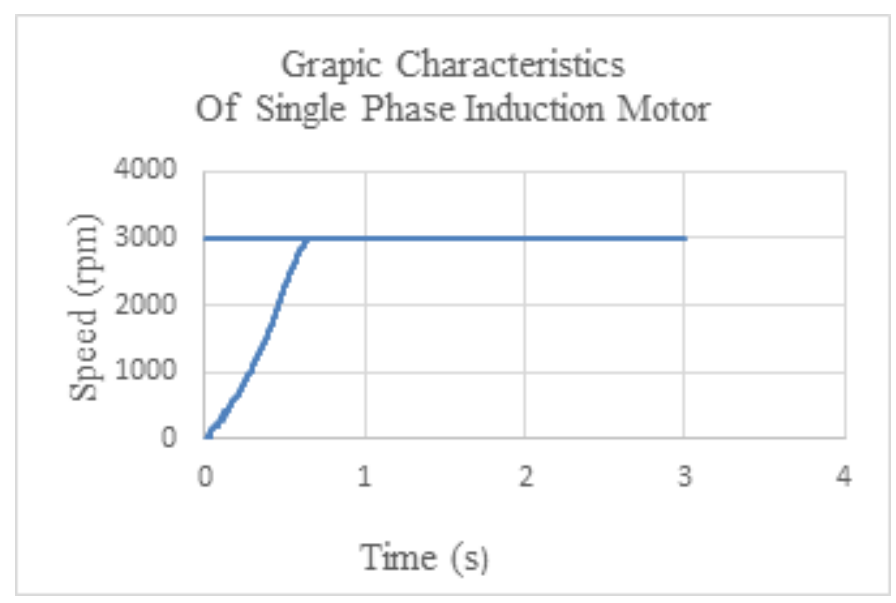

Figure 3. Response curve PI controller with Analytic method 
From the curve, it can be known that the single phase induction motor has nominal speed of $3000 \mathrm{rpm}$.

$$
\begin{array}{ll}
\begin{array}{l}
\text { Steady State } \\
(\text { Yss })
\end{array} & =2999 \mathrm{rpm} \\
\text { Time Settling } & =0.78 \mathrm{~s}
\end{array}
$$

(ts)

$$
\begin{array}{ll}
\begin{array}{l}
\text { Setting point } \\
(\mathrm{Xss})
\end{array} & =1500 \mathrm{rpm} \\
\mathrm{K} & =\frac{Y s s}{X s s} \\
\mathrm{~K} & =\frac{2999}{1500} \\
\mathrm{~K} & =1.99 \\
\mathrm{~T} & =\frac{t s}{5} \\
\mathrm{~T} & =\frac{0,78}{5} \\
\mathrm{~T} & =0.156 \mathrm{~s} \\
\tau=\tau \mathrm{i} & =0.156 \mathrm{~s}
\end{array}
$$

Open Loop Transfer Function PI:

$$
\begin{array}{ll}
\frac{C(s)}{U(s)} & =\frac{K}{T s+1} \\
\frac{C(s)}{U(s)} & =\frac{1.99}{0.156 s+1}
\end{array}
$$

If it aims to serve this plant in a double faster, it needs new value of $\mathrm{T}$.

$$
\begin{aligned}
& \mathrm{T}^{\prime} \quad=\frac{0.78}{10} \\
& \mathrm{~T}^{\prime}=0.078 \\
& \tau^{\prime} \quad=\frac{0.078}{5} \\
& \tau^{\prime} \quad=0.0156 \mathrm{~s} \\
& \mathrm{Kp}=\frac{\tau}{\tau^{\prime} \times K} \\
& \mathrm{Kp} \quad=\frac{0,156}{0.0156 \times 1.99} \\
& \mathrm{Kp}=5.032 \\
& \mathrm{Ki} \quad=\frac{K p}{\tau i}
\end{aligned}
$$

$$
\begin{array}{ll}
\mathrm{Ki} & =\frac{5.032}{0.156} \\
\mathrm{Ki} & =32.25
\end{array}
$$

\section{Design of PID Controller}

Calculating PID controller will use an analytic method. The main purpose is to determine the parameters of $\mathrm{Kp}, \mathrm{Ki}$ and $\mathrm{Kd}$ of the plant [17]. Data Yss, Xss, ts, and T for PID controller are same with PI controller because it still uses the same plan.

$$
\begin{array}{ll}
\mathrm{T} & =\frac{t s}{3} \\
\mathrm{~T} & =0.26 \mathrm{~s}
\end{array}
$$

Find Value of $\alpha$ :

$$
\begin{array}{ll}
\mathrm{A} & =\frac{1}{\tau} \\
\mathrm{A} & =3.84
\end{array}
$$

Find value of $\omega \mathrm{d}$

$$
\begin{array}{ll}
\omega \mathrm{d} & =\frac{\pi}{t p} \\
\omega \mathrm{d} & =4.6
\end{array}
$$

From the graphic we know that time peak of the plant happen at $0.68 \mathrm{~s}$. It means, time peak occurs before settling time.

Find $\omega n$ and $\xi$ :

$$
\begin{array}{ll}
\xi \omega \mathrm{n} & =\alpha \\
\omega d^{2} & =\omega n^{2}\left(1-\xi^{2}\right) \\
21.16 & =\omega n^{2}-\omega n^{2} \xi^{2} \\
21.16 & =\omega n^{2}-14.74 \\
\omega n^{2} & =35.9 \\
\omega \mathrm{n} & =5.99 \mathrm{rad} / \mathrm{s} \\
\xi \omega \mathrm{n} & =3.84 \\
\xi(5,99) & =3.84
\end{array}
$$




$$
\xi \quad=0.64
$$

Open Loop Transfer Function PID:

$$
\begin{array}{ll}
\frac{C(s)}{U(s)} & =\frac{K}{\left(\frac{1}{\omega n} S\right)^{2}+\left(\frac{2 \xi}{\omega n} S\right)+1} \\
\frac{C(s)}{U(s)} & =\frac{1.99}{(0.027 S)^{2}+(0.21 S)+1}
\end{array}
$$

Find value of $\tau^{\prime}$ :

$$
\begin{array}{ll}
\tau^{\prime} & =\frac{t s}{t s^{\prime}} \\
\tau^{\prime} & =\frac{0.78}{2} \\
\tau^{\prime} & =0.39
\end{array}
$$

Find value of $\tau i$ :

$$
\begin{aligned}
& \text { ti }=\frac{2 \times \xi}{\omega n} \\
& \text { i } \quad=\frac{2 \times 0.64}{5.99} \\
& \text { i } \quad=0.21
\end{aligned}
$$

Find value of $\tau \mathrm{d}$ :

$$
\begin{array}{ll}
\tau d & =\frac{1}{\tau i \times \omega n^{2}} \\
\mathrm{Td} & =\frac{1}{0.21 \times 5.99^{2}} \\
\mathrm{Td} & =0.13
\end{array}
$$

Find value of $\mathrm{Kp}$ :

$$
\begin{array}{ll}
\mathrm{Kp} & =\frac{1}{K} \times \frac{\tau}{\tau^{\prime}} \\
\mathrm{Kp} & =\frac{1}{1.99} \times \frac{0.26}{0.39} \\
\mathrm{Kp} & =0.33
\end{array}
$$

Find value of Ki:

$$
\begin{aligned}
& \mathrm{Ki}=\frac{K p}{\tau i} \\
& \mathrm{Ki}=\frac{0.33}{0.21} \\
& \mathrm{Ki} \quad=1.57
\end{aligned}
$$

Find value of $\mathrm{Kd}$ :

DOI : $\underline{\text { http://dx.doi.org/10.31963/intek.v8i1.2687 }}$

$$
\begin{array}{ll}
\mathrm{Kd} & =\mathrm{Kp} \times \tau \mathrm{d} \\
\mathrm{Kd} & =0.33 \times 0.13 \\
\mathrm{Kd} & =0.0429
\end{array}
$$

3. Design of Fuzzy Logic Controller

Fuzzy logic controller uses Mamdani method with input variables FIS (Fuzzy Inference System) error and $\Delta$ error [19]. Design Fuzzy logic controller describes the design of membership functions in input and output variables of the FIS and creates a basic rule [20]. Plot and parameter input variables FIS "error" are shown in Figure 4 and Table 1.

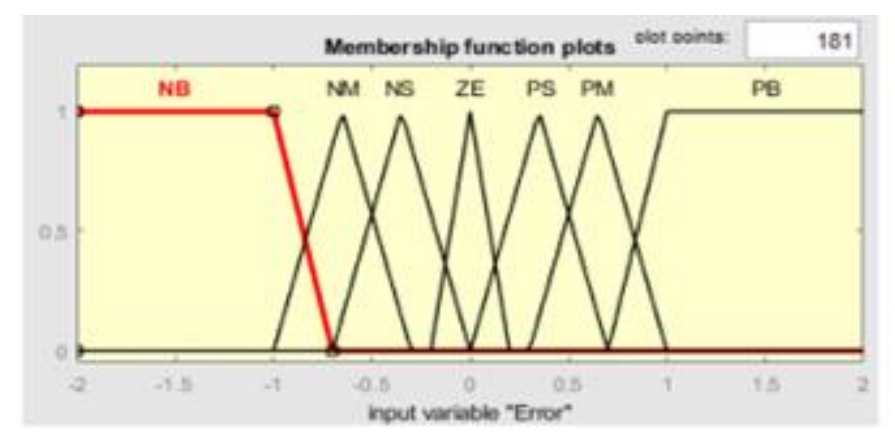

Figure 4. Plot of the error membership function in the Mamdani method

Table 1. Membership function parameter "error".

\begin{tabular}{|c|c|c|}
\hline Name & Type & Parameter \\
\hline NB (Negative Big) & trapezoid & $-2-2-1-0,7$ \\
\hline NM (Negative Medium) & triangle & $-1-0.65-0.3$ \\
\hline NS (Negative Small) & triangle & $-0.7-0.350$ \\
\hline ZE (Zero) & triangle & -0.200 .2 \\
\hline PS (Positive Small) & triangle & 00.350 .7 \\
\hline PM (Positive Medium) & triangle & 0.30 .651 \\
\hline PB (Positive Big) & trapezoid & 0.7122 \\
\hline
\end{tabular}

This value is obtained from the difference between setting point and speed read on the scope. Figure 5 shows the membership function " $\Delta$ error" and Table 2 shows the parameter of the membership function " $\Delta$ error". 


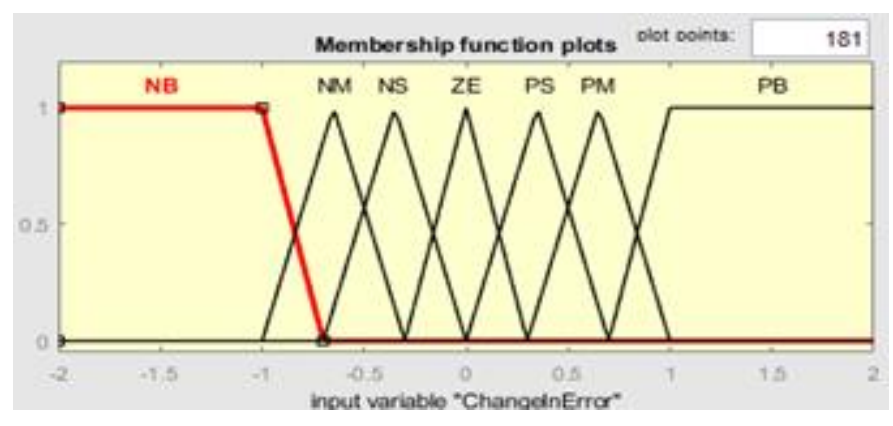

Figure 5. Plot of the $\Delta$ error membership function in the Mamdani method

Table 2. Membership function parameter " $\Delta$ error".

\begin{tabular}{|c|c|c|}
\hline Name & Type & Parameter \\
\hline NB (Negative Big) & trapezoid & $-2-2-1-0,7$ \\
\hline NM (Negative Medium) & triangle & $-1-0.65-0.3$ \\
\hline NS (Negative Small) & triangle & $-0.7-0.350$ \\
\hline ZE (Zero) & triangle & -0.300 .3 \\
\hline PS (Positive Small) & triangle & 00.350 .7 \\
\hline PM (Positive Medium) & triangle & 0.30 .651 \\
\hline PB (Positive Big) & trapezoid & 0.7122 \\
\hline
\end{tabular}

This value is obtained from the difference between error and speed read. Furthermore, Figure 6 shows output fuzzy membership function and Table 3 shows output fuzzy membership function parameters.

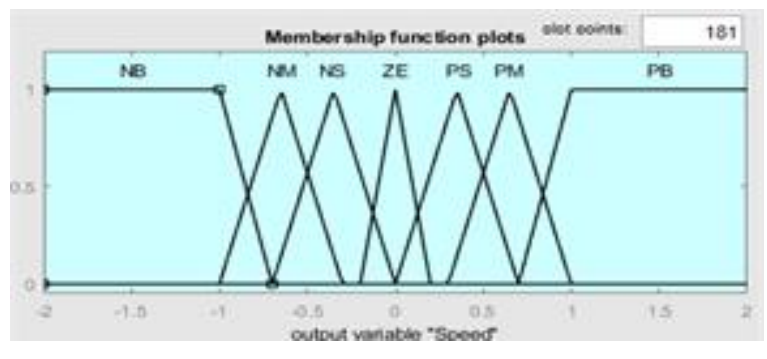

Figure 6. Plot of output fuzzy membership function in Mamdani method

Table 3. Membership function parameters output

\begin{tabular}{|c|c|c|}
\hline Name & Type & Parameter \\
\hline NB (Negative Big) & trapezoid & $-2-2-1-0,7$ \\
\hline NM (Negative Medium) & triangle & $-1-0.65-0.3$ \\
\hline NS (Negative Small) & triangle & $-0,7-0.350$ \\
\hline ZE (Zero) & triangle & $-0,200,2$ \\
\hline PS (Positive Small) & triangle & 00.350 .7 \\
\hline PM (Positive Medium) & triangle & 0.30 .651 \\
\hline PB (Positive Big) & trapezoid & 0.7122 \\
\hline
\end{tabular}

The number of rule base if - then rules shown in Table 4 is 49 , it uses the "and" connectors.
Table 4. Rule base

\begin{tabular}{|c|c|c|c|c|c|c|c|}
\hline \multicolumn{1}{|c|}{ "error" } & NB & NM & NS & ZE & PS & PM & PB \\
\hline NB & NB & NB & NB & NB & NM & NS & ZE \\
\hline NM & NB & NB & NB & NM & NS & ZE & PS \\
\hline NS & NB & NB & NM & NS & ZE & PS & PM \\
\hline ZE & NM & NM & NS & ZE & PS & PM & PB \\
\hline PS & NM & NS & ZE & PS & PM & PB & PB \\
\hline PM & NS & ZE & PS & PM & PB & PB & PB \\
\hline PB & ZE & PS & PM & PB & PB & PB & PB \\
\hline
\end{tabular}

Determining value of output fuzzy, it is adjusted to the expected setting point. For the rule base, the more rules that are applied, the higher the level of accuracy, so that many aspects are controlled [21].

\section{Results and Discussion}

In this simulation, a feedback control is applied to adjust system response to suit the necessity of plant (motor). Table 5 shows the results of the test at close loop with PI controller.

Table 5. Result of the test at close loop simulation with PI controller

\begin{tabular}{|c|c|c|}
\hline $\begin{array}{c}\text { Setting } \\
\text { point } \\
\text { (rpm) }\end{array}$ & $\begin{array}{c}\text { Nm } \\
(\mathbf{r p m})\end{array}$ & $\begin{array}{c}\text { \% } \\
\text { Error }\end{array}$ \\
\hline 3000 & 2976 & $0.8 \%$ \\
\hline 2700 & 2707 & $0.2 \%$ \\
\hline 2400 & 2397 & $0.1 \%$ \\
\hline 2100 & 2083 & $0.8 \%$ \\
\hline 1700 & 1702 & $0.1 \%$ \\
\hline 1500 & 1502 & $0.1 \%$ \\
\hline
\end{tabular}

In Table 5, it can be seen that the resulting error value is less than $1 \%$ and this number is considered successful for doing control.

Figure 7 shows a graph of the measured speed and reference speed in a close loop simulation test with PI controller. In the graph below, made a value $1500 \mathrm{rpm}$ and the measured speed is $1502 \mathrm{rpm}$. 


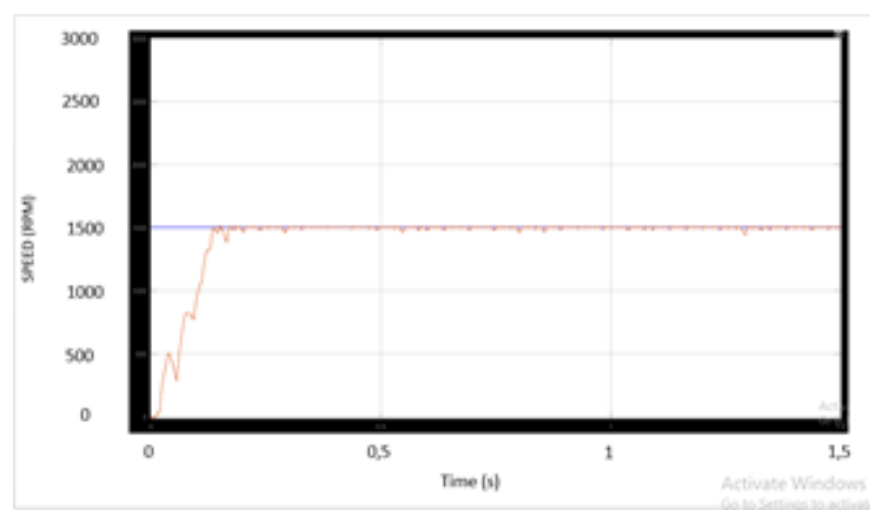

Figure 7. Graphic speed reference and measured speed with PI controller

Where:

Blue line : reference speed (setting point) $1500 \mathrm{rpm}$

Orange line: rated speed on the motor with a value 1502 rpm.

From the results with the PI controller, the system has a low error rate in speed regulation. Beside, with feedback control, speed response obtained has a lower oscillation rate than without giving control.

Next, a feedback control is employed to adjust system response to suit the necessity of plant (motor). Table 6 shows the results of the test at close loop with PID controller.

Table 6. Result of the test at close loop simulation with PID controller

\begin{tabular}{|c|c|c|}
\hline $\begin{array}{c}\text { Setting } \\
\text { point } \\
\text { (rpm) }\end{array}$ & $\begin{array}{c}\text { Nm } \\
(\mathbf{r p m})\end{array}$ & $\begin{array}{c}\text { \% } \\
\text { Error }\end{array}$ \\
\hline 3000 & 2967 & $1.1 \%$ \\
\hline 2700 & 2671 & $1.0 \%$ \\
\hline 2400 & 2375 & $1.0 \%$ \\
\hline 2100 & 2043 & $2.7 \%$ \\
\hline 1700 & 1689 & $0.6 \%$ \\
\hline 1500 & 1498 & $0.1 \%$ \\
\hline
\end{tabular}

It can be seen in table 6 that the resulting steady error is greater than the PI controller, and the largest error reaches $2.7 \%$. This number is quite large for a controller, because it is not close to the expected setting point.

Figure 8 shows a graph of the measured speed and reference speed in a close loop simulation test with PID controller. In the graph below, made a value $1500 \mathrm{rpm}$ and the measured speed is $1498 \mathrm{rpm}$.

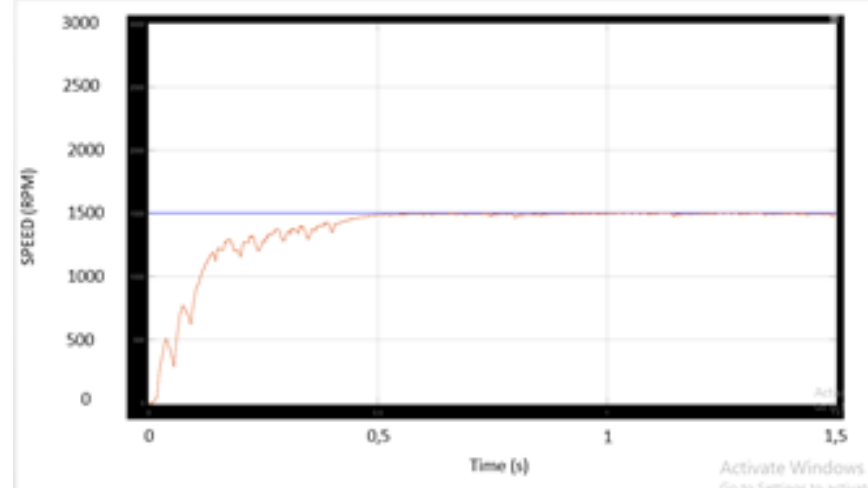

Figure 8. Graphic speed reference and measured speed with PID controller

Where:

Blue line : reference speed (setting point) $1500 \mathrm{rpm}$ Orange line: rated speed on the motor with a value 1502 rpm.

From the results of these data with the PID controller, the system has a higher error than PI controller in speed regulation. And based on Figure 8, the PID controller that used in this system has a larger settling time than the PI controller, but the system stability is better because the oscillations in some parts are lost.

On the PI and PID controllers some of the weaknesses can be seen, this can occur because of the improper tuning process carried out conventionally and in this system does not use variable come from calculations, these calculations are made as a benchmark for tuning new variable in order to produce better graphics.

To overcome these weaknesses, it will be juxtaposed with a fuzzy logic controller. This fuzzy does not use manual calculations. Table 7 shows the results of the test at close loop with fuzzy logic controller.

Table 7. Result of the test at close loop simulation with fuzzy logic controller

\begin{tabular}{|c|c|c|}
\hline $\begin{array}{c}\text { Setting } \\
\text { point } \\
\text { (rpm) }\end{array}$ & $\begin{array}{c}\text { Nm } \\
(\mathbf{r p m})\end{array}$ & $\%$ Error \\
\hline
\end{tabular}




\begin{tabular}{|l|l|l|}
\hline 3000 & 2991 & $0.3 \%$ \\
\hline 2700 & 2687 & $0.4 \%$ \\
\hline 2400 & 2387 & $0.5 \%$ \\
\hline 2100 & 2081 & $0.9 \%$ \\
\hline 1700 & 1687 & $0.7 \%$ \\
\hline 1500 & 1493 & $0.4 \%$ \\
\hline 1200 & 1195 & $0.4 \%$ \\
\hline
\end{tabular}

In Table 7, it can be seen that the resulting error value is less than $1 \%$ and this number is considered successful for doing control.

Figure 9 shows a graph of the measured speed and reference speed in a close loop simulation test with Fuzzy logic controller. In the graph below, made a value $1500 \mathrm{rpm}$ and the measured speed is $1493 \mathrm{rpm}$.

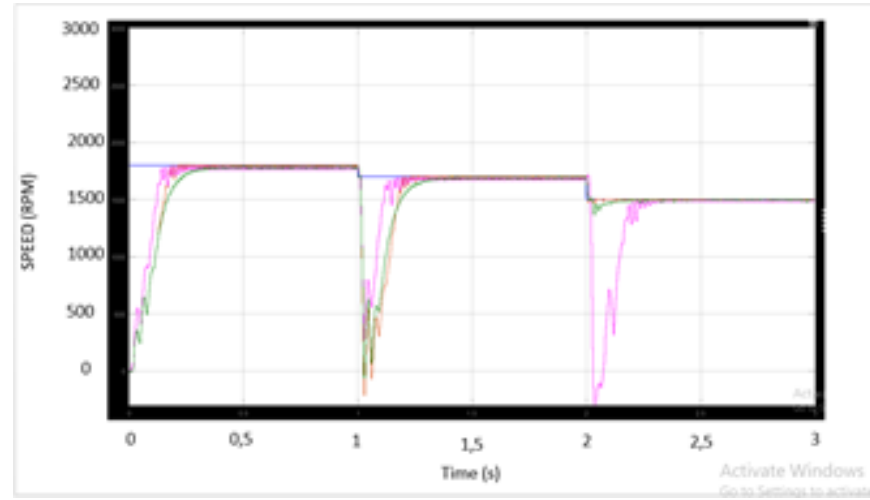

Figure 9. Graphic speed reference and measured speed with Fuzzy logic controller

Where:

Red line : Reference speed (setting point) $1500 \mathrm{rpm}$

Blue line: Rated speed on the motor with a value 1493 rpm

From the results of these data with the fuzzy logic controller, the system has a low error rate in speed regulation.

It can be seen in the Table 7 that there is an added setting point of $1200 \mathrm{rpm}$, it turns out that the fuzzy logic controller can still maintain the stability of the system. This can occur because the fuzzy logic controller has one pole so that it can freely control the system without depending on other poles. Difference with PI and PID, when they were given a setting point lower than the proper setting point (1500 rpm), they could not maintain their stability. This is because the control has more than one pole, so when from the beginning the setting point is designed, the controller will maintain the setting point only in that area. Figure 10 will show the comparison between the three controllers with variable speed.

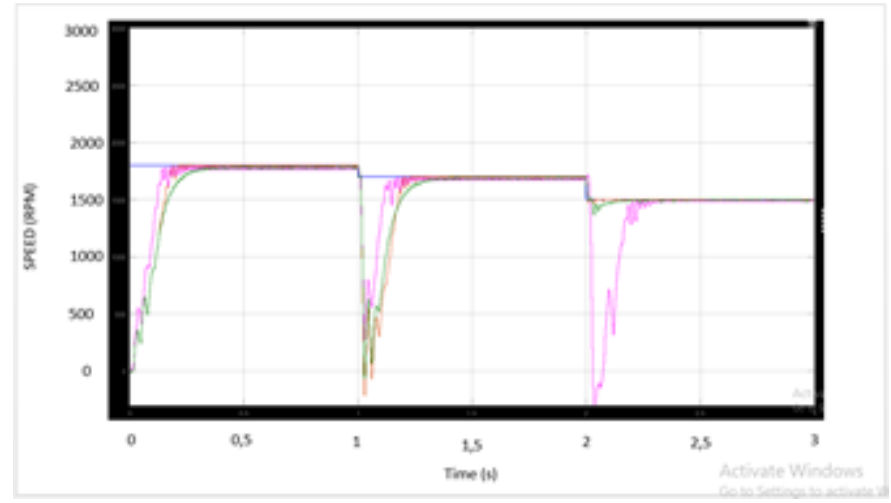

Figure 10. Comparison with variable speed

Where:

Blue line : Reference speed

Orange line: PI control

Green line : PID control

Pink line : Fuzzy control

Figure 10 is a comparison of variable speed. These variations are $1800 \mathrm{rpm}, 1700 \mathrm{rpm}$ and $1500 \mathrm{rpm}$. At $1500 \mathrm{rpm}$, the fuzzy control is the longest settling time control, however, these three controls can restore the speed to the expected setting point.

Table 8. Comparison results of several controls with variable speed

\begin{tabular}{|c|c|c|c|}
\hline Control & $\begin{array}{c}\text { Setting } \\
\text { point 1800 } \\
\text { (RPM) }\end{array}$ & $\begin{array}{c}\text { Setting } \\
\text { point 1700 } \\
\text { (RPM) }\end{array}$ & $\begin{array}{c}\text { Setting } \\
\text { point 1500 } \\
\text { (RPM) }\end{array}$ \\
\hline $\begin{array}{c}\text { Without } \\
\text { Control }\end{array}$ & 1767 & 1656 & 1380 \\
\hline PI & 1798 & 1702 & 1502 \\
\hline PID & 1794 & 1689 & 1498 \\
\hline Fuzzy & 1793 & 1687 & 1493 \\
\hline
\end{tabular}

From Table 8 it can be seen that he data exhibit a setting point of control comparison varies over time. It also shows the time it takes for a control to re-adjust in the new setting point after it has been changed. It appears that the fuzzy control has a long time to return 
after getting a disturbance. However, the three controls can still restore in steady state condition.

\section{Conclusion}

From the results, it can be drawn several conclusions as follow:

1. For conventional controller, the tuning results are not the same as the calculation results (approaching).

2. Conventional controller (PI \& PID), the setting point range is not as wide as fuzzy logic controller.

3. PI controller has number of $\mathrm{KP}=7.32$ and $\mathrm{KI}=0.005$. PI controller also has a result that carries a set point, the error is $0.1 \%$ and the settling time for this PI control is 0.20 seconds. However, the disadvantage of this control is that there is still some oscillation over time.

4. $\mathrm{PID}$ controller has number of $\mathrm{KP}=0.95$; $\mathrm{KI}=0.005$ and $\mathrm{KD}=0.04$. The control result of this PID is a single phase induction motor speed which has an error $0.1 \%$ against the setting point. The settling time of the PID controller is the longest of the other controllers, which is 0.51 seconds.

5. Fuzzy logic controller with 7 membership functions has the biggest error against the setting point, it is $0.4 \%$. And the settling time after getting this fuzzy controller becomes 0.25 seconds. However, this fuzzy controller has the most stable speed among other controllers.

\section{Acknowledgement}

Thanks to the Ministry of Research, Technology and Higher Education for funding research to the Research Center at the Electronic Engineering Polytechnic Institute of Surabaya.

\section{References}

[1] Stephen J Chapman, Electric Machinery Fundamentals, 4th ed., New York: McGraw Hill Book Companies, p. 380, 2005.

[2] Katsuhiko Ogata, Modern Control Engineering, Fift Edition, p. 567,2010
[3] Ye Naung, Schagun Anatolii, Ye Htet Lin, "Speed Control of DC Motor by Using Neural Network Parameter Tuner for PIController," IEEE Transactions on Power Electronics, p. 2152, 2019.

[4] M. C. Bosco, J. J. Guedes, M. F. Castoldi, A. Goedtel, E. R. Pires da Silva and L. F. Sanches Buzachero, "Estimation of parameters and tuning of a speed PI of permanent magnet DC motor using differential evolution," 2017 IEEE International Electric Machines and Drives Conference (IEMDC), 2017, pp. 1-6, doi: 10.1109/IEMDC.2017.8002318.

[5] Devendra Potnuru, J.S.V. Siva Kumar, "Design of a Front-End DCDC Converter for a Permanent Magnet DC Motor using Fuzzy Gain Scheduling," IEEE International Conference on Power, Control, Signals and Instrumentation Engineering (ICPCSI), 2017, p.1502.

[6] Dil Kumar T.R, Mija S.J, "Dynamic SMC Control Scheme with Adaptive Tuned PID Controller for Speed Control of DC Motor," IEEE International Conference on Industrial Technology (ICIT), 2015, p. 187.

[7] I. Jaziri, L. Charaabi and K. Jelassi, "A closed Loop DC Motor Control using low cost single-board microcontroller based on embedded Linux," 2016 International Conference on Electrical Sciences and Technologies in Maghreb (CISTEM), 2016, pp. 15, doi: 10.1109/CISTEM.2016.8066800.

[8] Ahmed J. Fattah, Dr. Ikhlas Abdel-Qader, P.E., "Performance and Comparison Analysis of Speed Control of Induction Motors using Improved Hybrid PID-Fuzzy Controller," IEEE International Conference on Electro/Information Technology (EIT), 2015.

[9] Divya Asija, "Speed Control of Induction Motor Using Fuzzy-PI Controller," IEEE Transactions on Power Electronics, vol. 15: p. 460, 2010.

[10] D. Kumar, R. A. Gupta and N. Gupta, "Minimization of current ripple and overshoot in four switch three-phase inverter fed BLDC motor using tracking anti-windup PI controller," 2017 IEEE International Conference on Signal Processing, Informatics, Communication and Energy Systems (SPICES), 2017, pp. 1-6, doi: 10.1109/SPICES.2017.8091355.

[11] P. Kumar and V. Agarwal, "A study of conventional and fuzzy PI controller CSI fed induction motor," 2010 International Conference on Power, Control and Embedded Systems, 2010, pp. 1-5, doi: 10.1109/ICPCES.2010.5698619.

[12] CAO Fengwen, WANG Yiwang, "Study and Application of Fuzzy PID Control-Based for FFU Motor Speed Regulation Control System," IEEE International Electric Machines \& Drives Conference (IEMDC), 2011, p. 160.

[13] Z. Pan, F. Dong, J. Zhao, L. Wang, H. Wang and Y. Feng, "Combined Resonant Controller and Two-Degree-of-Freedom PID Controller for PMSLM Current Harmonics Suppression," in IEEE Transactions on Industrial Electronics, vol. 65, no. 9, pp. 7558-7568, Sept. 2018, doi: 10.1109/TIE.2018.2793232.

[14] K. Sundaravadivu, B.Arun, K. Saravanan, ”Design of Fractional Order PID Controller for Liquid Level Control of Spherical Tank," IEEE International Conference on Control System, Computing and Engineering, 2011, p. 291.

[15] Dong Hwa Kim,'Tuning of PID Controller For Dead time Process Using Immune Based Multiobjective," IEEE MidSummer Workshop on Soft Computing in Industrial Applications Helsinki University of Technology, Espoo, Finland, 2005. 
[16] Yan-Jun Wu, Young-Gook Jung, Young-Cheol Lim, "AutoTuning Fuzzy PD Control Scheme for Output Voltage Control of Three-phase Z-source Inverter," IEEE International Symposium on Industrial Electronics, 2012, p. 222.

[17] Prashant S Malik, Sujay S Gawas, Imran Altaf Patel, Ninad P Parsekar, dkk, "Transient Response Improvement of DC to DC Converter By Using Auto-tuned PID Controller, "Proceedings of the 2 nd International Conference on Inventive Communication and Computational Technologies (ICICCT), 2018, p. 546.

[18] Subhash Chander,"Auto-tuned, Discrete PID Controller for DC-DC Converter for fast transient response," India International Conference on Power Electronics (IICPE), 2011.
[19] Sukamto., 2019, Induction Motor Speed Control Using Fuzzy Logic Controller, Journal of Electrical Electronic Control and Automotive Engineering (JEECAE), vol 4, hal 245-252.

[20] Sandeep, S, dan Mandeep, K., 2016, Gain Scheduling of PID Constroller Based on Fuzzy System, International Conference on Advances in Engineering and Technology (ICAET), Bangalore, Juni 4.

[21] Sharda, D, Chande., Pranoti, Khanke., 2017, Matlab Simulation Model Design of Fuzzy Controller based V/F Speed Control of Three Phase Induction Motor, International Journal of Engineering Research \& Technology (IJERT), vol 6, hal 10-15. 